\title{
Use of SPME and Chemometrics in Method Development for Food and Environmental Analysis of Pesticide Residues
}

\author{
Guan Huat Tan*, Kah Hin Low and Adijat Awoniran
}

Department of Chemistry, University of Malaya, 50603 Kuala Lumpur, Malaysia

\begin{abstract}
The need to analyze multi pesticide residues continues to be imperative and applying a suitable experimental design remains the core to achieving a comprehensive chemical analysis. The pretreatment of a sample has been found to be the most important rate-determining step as it affects the instrumental process and data analysis. The use of the SPME technique coupled with GC-MS to determine multi-residue pesticides is found to be applicable in environmental, pharmaceutical, food, clinical, forensic samples in three modes (DI-SPME, HS-SPME and MD-SPME). This has gained much recognition due to its advantage over the classical or previous sample pretreatment methods such as SPE, LLE, LDME, HFME and DLME. Before applying SPME coupled to a GC-MS detector, several conditions need to be met in order to accomplish enhanced extraction rate, efficiency and sensitivity of experimental procedures. The large numbers of data sets obtained with the advent of various instrumental techniques can be analyzed speedily by applying chemometric methods to screen the various parameters affecting the calibration methods by statistical application so as to achieve the best optimization of the experiment. This review aims at looking at the different chemometric methods for multivariate parameter optimization in experimental design for the analysis of pesticide residues in water.
\end{abstract}

Keywords: SPME; GC-MS; Chemometrics; Pesticides; Experimental design

\section{Introduction}

Resolving chemical analysis such as in environmental, industrial and biological samples to obtain reproducible and accurate results starting from the start-up stage (sample pre-treatment) to data analysis, in determining multi pesticide residues involves the ability to choose an appropriate experimental design. Sample pretreatment is a crucial step in chemical analysis, therefore the relevant methodology to achieve a safer, cheaper and more accurate determination must be considered [1]. Several methods such liquid-liquid extraction, pressurized liquid extraction, accelerated solvent extraction, microwave assisted solvent extraction, soxhlets extraction, supercritical fluid extraction, purge and trap, solid phase extraction and other methods have been reported in the literature on its applicability to determine trace pesticide residues [2-5] but most are found to be expensive, time-consuming, use of large volumes of toxic organic solvents [6,7], hence the need to find a method that will solve the above shortcomings.

Solid Phase Microextraction (SPME) is an extraction method developed by Pawliszyn and Arthur to pretreat samples either in solid, liquid or gas phase [8], and it is based on reaching an equilibrium between the analyte in the sample matrix and extraction phase [9-11]. The technique involves the use of either self-made or commercially available fibers as shown in Figure 1, coated on a fused silica wire for the purpose of sampling, extraction and desorption of the analyte with an appropriate instrumental technique such as Gas Chromatography (GC), Capillary Electrophoresis (CE), High Performance Liquid Chromatography (HPLC), Matrix-assisted laser desorption/ionization (MALDI) and others, coupled with detection techniques such as Mass spectrometry detection (MS), Electron Capture Detection (ECD), Flame Photometric Detection (FPD), Nitrogen-Phosphorus Detection (NPD), Diode Array Detection (DAD) [12,13]. The use of SPME-GC has been applied for the analysis of volatile or semi volatile organic compounds such as, PAHs, PCBs, pesticides, phenols compared to HPLC [14] and has been reviewed in several studies to solve the various problems posed by previous sample pre-treatment methods. The SPME technique can be regarded as being greener, [15] faster, relatively cheaper, versatile, and can be automated with short extraction time as well as being more accurate and simple procedure [16].

SPME was known to be limited to use in organic compound determinations such as poly aromatic hydrocarbons (PAHs), volatile organic compounds (VOCs) and volatile compounds such as benzene, toluene, ethyl benzene and xylene, BTEXs, etc. [17]. However in recent studies, it has been shown to be used to determine metal inorganic compounds as the target analyte [18]. With the increasing development of analytical instruments such as gas chromatography (GC) and others, this leads to the generation of complex data with limited analytical time to process, therefore, it has become very imperative to be able to analyze these generated data with the best approach such as using a chemometric tool. The automation of the analytical instrument is very critical since the classical method of sample pretreatment is very laborious and about $75 \%$ of the time is spent on this stage, hence the need to apply a less time-consuming analytical process [19]. Chemometrics uses different tools for collecting and analyzing chemical data with the aim to design the experiment by screening and optimizing the various experimental parameters.

Several review articles have established the use of SPME and chemometrics in chemical analysis and the aim of this review is to present recent development or modifications of SPME and the use of

${ }^{*}$ Corresponding author: Guan Huat Tan, Department of Chemistry, University of Malaya, 50603 Kuala Lumpur, Malaysia, E-mail: ghtan@um.edu.my

Received September 22, 2015; Accepted September 24, 2015; Published November 02, 2015

Citation: Tan GH, Low KH, Awoniran A (2015) Use of SPME and Chemometrics in Method Development for Food and Environmental Analysis of Pesticide Residues. Chem Sci J 6: 110. doi:10.4172/2150-3494.1000110

Copyright: (c) $2015 \mathrm{Tan} \mathrm{GH}$, et al. This is an open-access article distributed under the terms of the Creative Commons Attribution License, which permits unrestricted use, distribution, and reproduction in any medium, provided the original author and source are credited. 
Citation: Tan GH, Low KH, Awoniran A (2015) Use of SPME and Chemometrics in Method Development for Food and Environmental Analysis of Pesticide Residues. Chem Sci J 6: 110. doi:10.4172/2150-3494.1000110

Page 2 of 8

chemometrics in analyzing environmental samples such as pesticides in food, water, soil and other forms of sample systems.

\section{Experimental Methods}

\section{Consideration when developing an SPME method}

When considering the SPME method for sample preparation and pretreatment, the focus is to achieve a greater extraction rate, efficiency and sensitivity; hence many parameters need to be optimized for enhanced detection and sensitivity.

\section{Choice of fibre}

The choice of fibre is one of the most important steps in the SPME method and it depends on the concentration level and range, sample complexity, analyte polarity and molecular weight /size of the sample matrix. Fibres are generally classified into four categories, namely: coating type, film thickness, polarity and absorbent or adsorbent. The compositions of the fibre are as follows: pure liquid polymer (PDMS, PA) and mixed film consisting of solid particles and liquid polymer (carboxen-PDMS, DVB-PDMS). The pure liquid polymer extract through absorption (analyte diffuse and dissolve into the fibre) while for porous particle fibre, extraction is via adsorption (analyte residing as a mono-layer). Mixed films combine extraction through absorption of liquid polymer with adsorption of porous particle [20]. All SPME fibres have the ability to a certain extent to extract both polar and nonpolar analytes but the overall polarity of the coating determines its suitability.

The characteristics of the fibre include polarity, surface activity, porosity, mechanical strength and thickness [10,21]. The reuse of fibre is possible for about 50-100 extractions but due to its fragility; excessive usage will lead to its breakage during injection or agitation. However, this limitation has been improved by recent development of a metal alloy with elastic property on which the fibre is coated $[20,22]$. The extraction time of an SPME fibre depends on the thickness; hence, for very thick fibers longer extraction times are necessary for better recoveries, while for thinner fibres the extraction time is shorter. Previously, commercially made fibres from liquid polymeric coatings (PDMS, PA) were the only available fibres but recently, newly specialized fabricated fibres have been developed and several new methods for deposition of fibre are shown in Figure 2 [23,24]. Chong et al used a sol gel-PDMS and it was thermally stable when placed in a heated GC injector at $320^{\circ} \mathrm{C}$ unlike the commercially available PDMS which bleeds at approximately $200^{\circ} \mathrm{C}$ inside the heated GC injector $[25,26]$.

PDMS is the most commonly used fibre and have been employed for several applications such as determination of several main groups of pesticides in water at ppb levels [27-29], waste water [3032], soil [33], food [33,34], and biological fluids [35,36,30]. There is a limited range of stationary phase and this gives rise to restriction for applicability [10].

\section{Derivatization}

For complex sample matrices which may pose difficulty in extraction such as ionic and polar compounds, it is necessary to derivitize the sample so as to make the sample extraction process easier and to aid better detection. Derivitization can be applied before, during or after extraction, post derivitization only aids chromatographic separation and detection [37] e.g., dilution, centrifugation, use of organic solvent, pre-concentration [38-43]. This is done to prevent irreversible absorption of large molecules from the sample matrix, thereby increasing the life span of the fibre coating and hence improve SPME performance.

\section{Exraction mode of SPME}

Three extraction modes exist in the use of SPME fibre, namely direct immersion, headspace, and membrane protecting SPME as shown in Figure 3.

Direct Immersion Solid Phase Microextraction (DI-SPME): Direct Immersion method is based on the insertion of fibre-coated polymeric stationary phase just below the sample matrix (Figure 3),

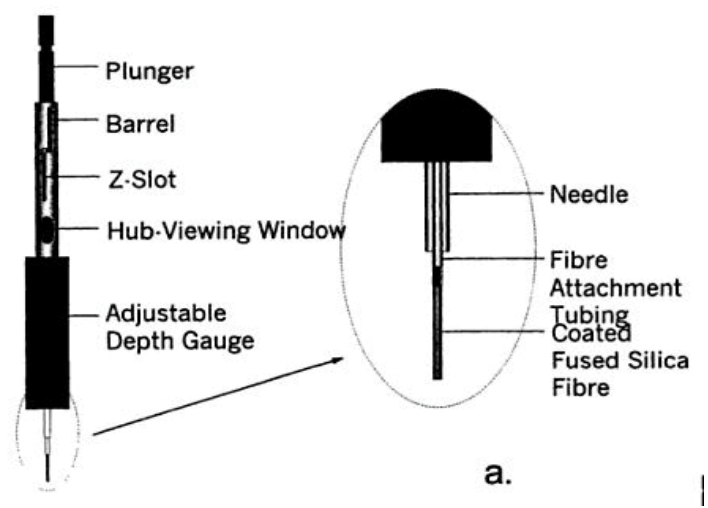

Figure 1: Commercial SPME device [18].

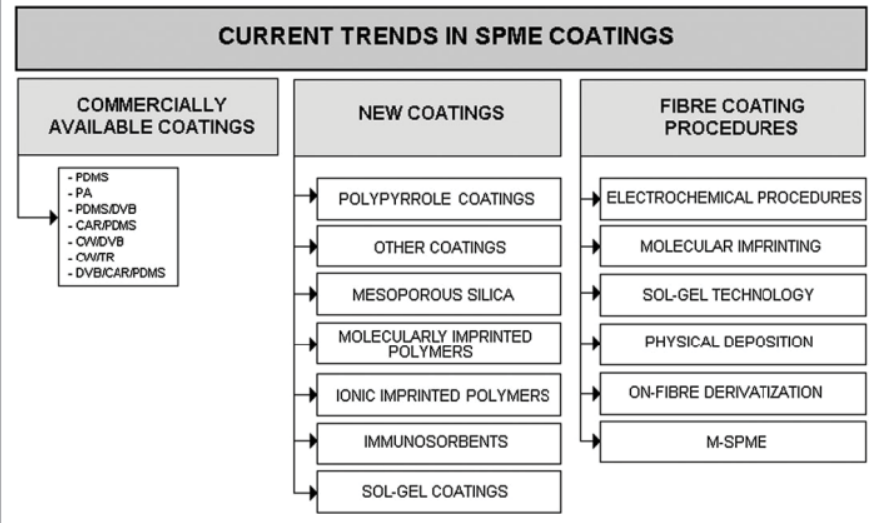

Figure 2: Current trends in SPME coatings [15]

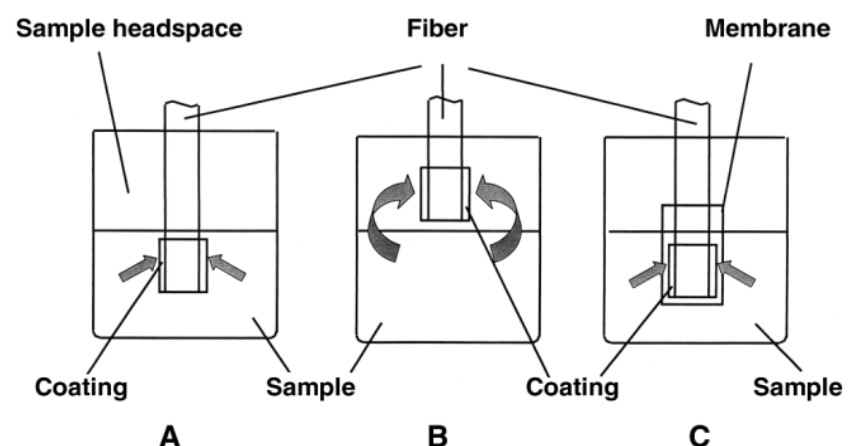

Figure 3: Mode of SPME extraction [44]. 
throughout the extraction time for the absorption of the analyte of interest. In achieving this, a certain level of agitation is made on the sample matrix in which the extent is dependent on either it is a gaseous, aqueous or solid sample. A gaseous sample will require a lower extent of agitation while the others will require more and this can be achieved by using sonication, stirring, rapid fibre or vial movement [44]. The extracted analyte is then thermally desorbed in the pre-heated GC [45]. DI-SPME can be used to analyse low polar and low volatile organic compounds unlike HS-SPME but apparently, there is an additional sample pre-treatment, which requires derivitization before subjecting it to SPME [46]. This is done to prevent irreversible absorption of large molecules from sample matrix, thereby increasing life span of the fibre coating hence improve SPME performance. Different pesticide groups in ground and surface water were analysed using DI-SPME-GC-MS [47].

Headspace Solid Phase Microextraction (HS-SPME): Headspace Solid Phase Microextraction (HS-SPME) has three equilibrium phases namely, headspace, fibre coating and aqueous phase, as shown in Figure 3. The setup is similar to that of DI-SPME except that the headspace is placed above the sample matrix. The analyte of interest has to pass through the vapour phase before extraction is attained. The decision to use HS-SPME instead of DI-SPME is based on the sample type i.e., considering the analyte volatility and the matrix composition. Hence for highly volatile compounds and dirty matrices, HS-SPME is employed.

This technique requires a shorter operation time due to the higher diffusion coefficient of the analyte for example, gaseous analyte [48]. For semi-volatile compounds (gaseous phase) when the concentration is low, this might lead to low extraction rate, but it can be enhanced by agitation and increase in operating temperature [49], reduced sample contamination and derivitisation i.e., minimal use or absence of solvent, better reproducibility, longer life span of fibre coating, and automation is achievable by connecting to an auto sampler, resulting in larger sample throughput. Unfortunately, HS-SPME has some drawbacks in its usage, and there is a shortage of commercially available range of stationary phases [10], reproducibility of fibre to fibre coating, limited to volatile compounds, carry-over effects is very noticeable, laborious and time-consuming to optimise the experimental variables and conditions [50].

Membrane Protection Solid Phase Microextraction (MPSPME): Since the extraction of analyte from sample matrix with either dirty or high molecular weight components leads to damage to the fibre coating when immersed directly into the sample, MP-SPME technique is practiced to prevent this since there is a barrier (membrane, usually silicon tube) between the sample and fibre coating, (Figure 3). The inert gaseous analyte passes through the membrane and enters the sorption trap where it is retained for desorption in the GC column injector. This prolongs the life span of the fibre coating, by disallowing the migration of interferences, but there is a decrease in diffusion of the analyte due to the presence of the membrane, therefore, the extraction time is longer. This can be enhanced by increasing the operating temperature which leads to shorter extraction time [51].

Determination of extraction time: To attain equilibrium during SPME extraction, the time taken depends on several factors such as fibre coating (thickness), agitation conditions, physico-chemical property of analyte (volatility), and concentration of analyte. The requirement of extraction sensitivity determines the extraction time which can range from minutes to hours. When the highest sensitivity is required, the analyte extraction coating is maximized, hence, more time is involved but when highest sensitivity is not necessary, there is a reduction in extraction time [21]. Extraction time must be optimized for each determination and the operating conditions must be consistent. Typical extraction time is illustrated in Figure 4.

Optimization of extraction conditions: The extraction parameters that affect the rate and efficiency include the following: - time of extraction, temperature, time of desorption, $\mathrm{pH}$ in acidic herbicides of chlorophenol derivatives [31], ionic strength [30] and sample agitation.

Enhanced extraction can be achieved by applying the following:

- Adjusting the fibre coating - when the fibre coating is made thicker or longer, it leads to an increase in the extraction i.e., this doubles the mass of analyte absorbed during extraction.

- Temperature adjustment to suit the analyte in question, hence for high boiling point analyte, the temperature is increased and lower temperature for lower boiling point anayte. The rationale for this is that an in increase in diffusion leads to a decrease in distribution constant hence, a faster equilibration time is achieved.

For organochlorine (OCPs), organophosphorus (OPPs) and triazine pesticides, it has been reported that the increase in extraction temperature to about $60^{\circ} \mathrm{C}$, has led to better recoveries of these pesticides [34,52-55].

- The use of more polar polymer (coatings), for polar compounds aids in greater extraction ability.

- Addition of $\mathrm{NaCl}$ or $\mathrm{NaSO}_{4}$ to aqueous samples leads to increased extraction ability, although, in other studies $[56,57]$, there was an insignificant change in the extraction efficiency by the addition of salt.

- $\mathrm{pH}$ adjustment for slightly acidic or alkaline compounds [58].

- Sample agitation helps to reduce the diffusion layer, hence equilibration is attained faster. Several agitation methods were used in analyzing different triazine pesticide groups, e.g., magnetic stirrer, flow through extraction and fibre vibration. All methods of agitation came in handy but the fibre vibration has an added advantage of being able to be automated hence an increase in sample throughput [59].

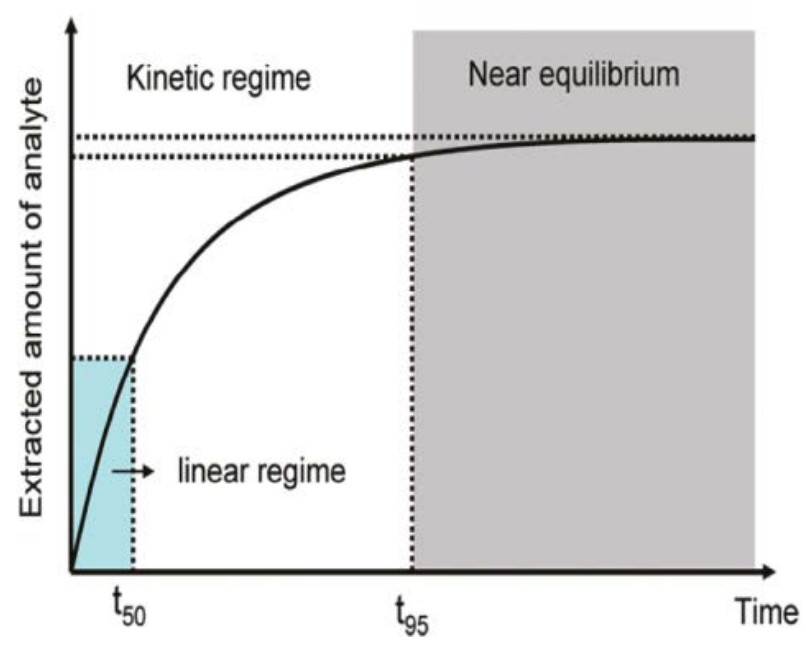

Figure 4: Typical extraction time profile [52] 
- Geometric enhancement, such as using cooled SPME devices [6062], electrochemically enhancing SPME by putting on the suitable potential, e.g., potentiometry and cyclic voltammetry $\mathrm{CV}$ to fibre coating for both extraction and desorption stage [63-65], magnetin-tube SPME which is useful for diamagnetic analytes. The principle is based on the use of a controlled magnetic field, that leads to pre-concentration of analyte attributable to the difference in magnetic field generated between the analyte of interest and the sample matrix [66] and using purge-assisted headspace SPME to increase mass transfer of analyte either from an aqueous or gaseous sample matrix, e.g., 7-nitrobenz(a)anthracene, 6-nitrochrysene, which are both high boiling point compounds $[52,67]$.

\section{Instrumentation}

Good performance is a major requirement for the selection of an analytical instrument in order to achieve great separation and detection of analyte. Although several instruments have been reported to be coupled with SPME such as GC, CE, HPLC, SFC, MALDI, Nano spray MS interface, GC is the most frequently applied and for rapid desorption of analyte, conditions such as a narrow needle (to increase the flow leading to efficient desorption) and with the splitter turned off during injection [68].

GC-MS is more popular since it can both be coupled and has adjustable selectivity by applying appropriate molecular and fragment ions to prevent interferences from the sample matrix [69]. GC coupled to mass spectrometry usually uses electron ionization (EI) and chemical ionization (CI). EI is mostly used for pesticide analysis $[70,71]$ while $\mathrm{CI}$ has a better selectivity but signal intensity varies and offers less information due to fewer fragments [72]. The database of several pesticides determination using electron ionization (EI) mass spectra are readily available.

\section{Optimization of desorption condition}

At equilibrium, the extraction process is achieved and completed, followed by desorbing the extracted analyte into a thermally heated injected GC or HPLC. In achieving efficient desorption, a high linear flow rate is necessary, and the analyte must be removed immediately from the fibre coating to prevent interaction with coatings [73].

\section{Calibration method}

SPME calibration is applied to ensure that no interference is contributed by the fibre or instrument, and is achieved by running a fibre blank. The fibre must be conditioned before and after analysis in the GC injector, and post-conditioning is necessary if the sample matrix has a high molecular weight. When the distribution constant can be estimated by using the physicochemical and chromatographic parameters or from literature, then the calibration procedure can be omitted otherwise a suitable calibration method must be employed. Three different calibration methods can be employed, namely, classical method, equilibrium method and diffusion-based calibration [74].

\section{Screening and optimization for SPME-GC-MS using chemo- metrics tools}

In modern day studies, the use of analytical instruments gives rise to the possibility of generating large data sets which may lead to a severe data analysis problem. Obtaining a faster and better data quality approach with less laboratory work, the chemometrics approach can be employed to achieve this objective. Chemometrics uses mathematics, logic and statistics to achieve optimized experimental design and ability to analyze data from the chemical system [75]. It has several applications in medical analysis, petrochemicals, industrial, pharmaceuticals (drug design), food chemistry, process analytical, biological (metabolomics, proteomics), environmental [76,77]. The chemometric method (method or tools) includes; experimental design, signal analysis, pattern recognition, calibration and general statistics [78].

\section{Experimental design}

Statistical analysis of data is not the most important stage of the experimental procedure, but the design of experiment is very crucial to obtain meaningful data [79]. The results of a good experimental design includes screening (elimination of variables), optimization (improve chromatographic separation), saving time and quantitative modeling (models from mathematical origin). There exist different techniques in achieving excellent design e.g., factorial design, fractional factorial design, Placket-Burman, central composite design, mixture design and response surface design can be used [80]. In the chemical system several variables (homogeneous or heterogeneous) affect the yield or response. These require proper screening and optimization without having to compromise the quality or response value. To achieve this, the experimental design chosen depends on the aims and objectives of the researcher, ability to determine which factors influence the yield/ response and overall compatibility [81].

Complete factorial design: In contrast to the univariate design technique, which involves the varying of one factor at a time while other factors are held constant, i.e., a single factor is used to measure response, the complete factorial design or screening design involves the consideration of all possible factors simultaneously to determine effect on response or yield $[81,82]$. The variables can either be qualitative or quantitative, be easy to perform and can be used for estimation if there is any interaction between the factors. Factorial design usually involves a two-level study i.e., low and high, to eliminate the need for several experiments (univariate design). The main disadvantage of screening design is that the number of experiment increases rapidly leading to an unacceptable work load. When the level of factor is too close or too far apart, the response effect is deemed to be insignificant or be out-ofrange [83]. This can be avoided by careful investigation of the literature or by using a higher level such as the three-level designs. Two-level fractional factorial design was used to optimize the determination of contaminants in Duero River by the SPME technique. Four variables (sample time, sorption temperature, desorption temperature, salt concentration) were screened and it was established that sample time was the most significant factor [84] in this study. Abdul Rauf and Tan used the experimental factorial design method to determine some multiclass pesticide residues in apples using HS-SPME-GC-MS [85].

Fractional factorial design: As stated above, the shortcoming of the complete factorial design method is the large number of experiments e.g., using a 10-factor at two-level design would require 1024 experiments, which is very impracticable. It makes factor screening inefficient due to the omission of relevant factors. The fractional factorial design is thereby used to solve this problem by using certain fractions such as half, one-quarter, one-eighth of the experiments from the complete factorial design. The factors must be replicates, and only applicable to level two and with a maximum power of experiments of 2 [86,87]. Six variables were screened using $2^{(6-2)}$ fractional factorial design, and the significant variables were optimized using CCD during the determination of volatile phenols in water by fiber-SPME [88].

Plackett-Burman design (screening): This is suitable for four-level experiments $-4^{\mathrm{n}}$ and gives information on the main effects of factors 
Citation: Tan GH, Low KH, Awoniran A (2015) Use of SPME and Chemometrics in Method Development for Food and Environmental Analysis of Pesticide Residues. Chem Sci J 6: 110. doi:10.4172/2150-3494.1000110

\begin{tabular}{|c|c|c|c|c|c|c|}
\hline Matrix & $\begin{array}{c}\text { Instrument/ } \\
\text { detection }\end{array}$ & SPME fibre & Analyte & Extraction mode & Ref & Chemometric tool \\
\hline Aquaculture-seawater & GC-MS/MS & PDMS & OPPs and pyrethroid & SPME & [94] & CCD \\
\hline Grape and apple & GC-MS & - & Pesticides & SDME & [88] & Multivariate strategy \\
\hline Water & GC-ECD & $\mathrm{PA}$ & OCPs & SPME & [95] & Response surface methodology \\
\hline Greek wine & GC-MS & $\begin{array}{c}\text { PDMS, PDMS/DVB, CAR/PDMS, PA, } \\
\text { DVB/CAR/PDMS }\end{array}$ & Primary aromatics & HS-SPME & [18] & 2-level Placket-Burman \\
\hline Food & GC-ECD & PDMS/DVB & & SPME & [96] & $2^{6-2}$ fractional factorial, CCD Design \\
\hline Human plasma & GC-MS & & Pentachlorophenol & HS-SPME & {$[97]$} & $\begin{array}{l}\text { two-level full factorial design and } \\
\text { CCD }\end{array}$ \\
\hline Cow milk & GC-MS & PDMS-DVB & OPPs & HS-SPME & [98] & Multivariate factorial design \\
\hline White wine & GC-MS & DVB-CAR-PDMS & Fungicides & SPME & [99] & RSD \\
\hline Grape, must and wine & $\begin{array}{l}\text { GC-NPD } \\
\text { GC-ECD }\end{array}$ & & Fungicides & & {$[100]$} & PLS \\
\hline Bovine milk & GC- $\mu \mathrm{ECD}$ & PDMS-DVB & pyrethroid pesticides & SPME & [101] & $2^{5-1}$ fractional factorial design \\
\hline
\end{tabular}

Table 1: Sample pretreatment for different sample matrix using SPME-GC and its corresponding chemometric method employed.

and not their interactions. The 2-level Plackett-Burman design also called Taguchi designs or Hadamard matrices, was the chemometric tool used during the extraction and determination of primary aromatics in wine using SPME-GC-MS. This was used to evaluate variables and for further optimization [19].

Central Composite Design (CCD): All the above-mentioned experimental designs are used to screen for relevant factors, and CCD is used for more detailed design by optimizing the factors and give detailed quantitative response information, when no replicates are available. The sodium chloride content and extraction time were established as the significant variables after screening and optimization of the experimental procedure using fractional factorial design and CCD for the determination of methyl-tert-butyl in water using HSSPME-GC-FID was investigated [89,90]. In 2009, Elpiniki used CCD to optimize the extraction of multiclass pesticide residues in grapes using SDME-GC-MS [91].

Mixture design: This involves mixtures of several factors whose sum total is a constant value [92].

Response surface design: Response surface design is used for the most important variables, i.e., their optimal conditions and it is divided into symmetrical and asymmetrical designs [77,93]. Barreiro et al. applied screening and response surface design during the experimental design for the determination of alachlor in water using SPME [94].

Multivariate calibration: Multivariate calibration methods use mathematical tools for chemical analysis when simultaneous measurement of variables or factors is required to achieve selectivity and consistency [95]. Multivariate calibration can be applied to near Infrared (NIR), reflectance analysis as well as to NMR, IR, UV, chromatography (GC, HPLC), thermal analysis, image analysis and electrophoresis [96]. The methods include partial least squares (PLS), principal component regression (PCR), classical least squares (CLS), inverse least squares (ILS), cluster analysis, discriminant analysis and artificial neutral network.

General statistics: The use of statistics to report and evaluate data is achieved by using mathematical tools. Statistics is used to determine errors in analysis which can be determinate (procedural or instrumental) or indeterminate (instrumental noise) to gain some level of confidence in the generated data. The common statistical technique includes t-test which is used to test for significance of the individual term, f-test, outlier test, ANOVA, etc. Determination of pesticides analyte with various sample matrices using SPME-GC-MS and its chemometric tools [97-101] are shown in Table 1.

\section{Conclusion}

The complexity of a chemical system for analysis requires the development of a suitable experimental design so as to achieve comprehensive results. Prior to the use of SPME certain conditions must be fulfilled so as to accomplish enhanced extraction rate, efficiency and sensitivity in order for the sample to be extracted efficiently. The application of chemometric tools can be used to optimize the different variables or parameters affecting the extraction using the SPME technique and to analyse obtained data from instrumental response.

\section{Acknowledgements}

The authors would like to thank Zhouyao Zang, Agata Spietelun, Prof. Janusz Pawliszyn and $\mathrm{H}$. Ho for permission to use their illustrations in this review write-up. Financial assistance for this project from the University of Malaya, UMRG Grant RG227-12AFR and PPP Grant No: PG042-2014A is also kindly acknowledged.

\section{References}

1. Souza-Silver EA, Risticevic S, Pawliszyn J (2013) Recent trends in SPME concerning sorbent materials, configurations and in vivo applications. Trend Anal Chem 43: 24-36.

2. Boyd-Boland AA, Pawliszyn J (1995) Solid Phase Microextraction of Nitrogen Containing Herbicides. J Chromatogr 704: 163-172.

3. De Koning S, Janssen HG, Brinkman UAT (2009) Modern Methods of sample preparation for GC Analysis. Chromatograhia 69: 33-78.

4. Park JH, Md Mamun IR, Choi J, Abd El-Aty AM, Assayed ME, et al. (2010) Development of a multiresidue method for the determination of multiclass pesticides in soil using GC. Biomedical Chromatography 24: 893-901.

5. Fernandes C, Santos-Neto AJ, Rodrigues JC, Alves C, Lancas FM (2007) Solid-phase microextraction-liquid chromatography (SPME-LC) determination of fluoxetine and norfluoxetine in plasma using a heated liquid flow through interface. J Chromatogr B 847: 217-223.

6. Beltran J, Lopez FJ, Cepria O, Hernandez F (1998) Solid-phase microextraction for quantitative analysis of organophosphorus pesticides in environmental water samples. J Chromatogr A 29: 257-263.

7. Font G, Mañes J, Moltó JC, Picó Y (1993) Solid-phase extraction in multiresidue pesticide analysis of water. J Chromatogr 642: 135-161.

8. Arthur CL, Pawliszyn J (1990) Solid Phase Microextraction with Thermal Desorption Using Fused Silica Optical Fibers. Anal Chem 62: 2145-2148.

9. Pawliszyn J (2012) Comprehensive sampling and sample preparation. Analytical Techniques for scientist: Academic press.

10. Dietz C, Sanz J, Cámara C (2006) Recent developments in solid-phase microextraction coatings and related techniques. J Chromatogr A 1103: 183-192.

11. Sun M, Feng J, Qui H, Fan L, Li L, et al. (2013) A solid phase microextraction 
Citation: Tan GH, Low KH, Awoniran A (2015) Use of SPME and Chemometrics in Method Development for Food and Environmental Analysis of Pesticide Residues. Chem Sci J 6: 110. doi:10.4172/2150-3494.1000110

fibre with carbon nanoparticles as sorbent material by a simple flame-based preparation process. J Chromatography A 1300: 173-179.

12. Pawliszyn J (1999) Applications of solid phase microextraction. RSC, Cornwall, UK.

13. Vuckovic D, Cudjoe E, Hein D, Pawliszyn J (2008) Automation of solid-phase microextraction in high-throughput format and applications to drug analysis. Anal Chem 80: 6870-6880.

14. Chen J, Pawliszyn J (1995) Solid phase microextraction coupled to high performance liquid chromatography. Anal Chem 67: 2530-2533.

15. Spietelun A, Pilarczyk M, Kloskowski A, Namienik J (2010) Current trends in solid-phase microextraction (SPME) fibre coatings. Chem Soc Rev 39: 45244537.

16. Pawliszyn J (1997) Solid Phase Microextraction: Theory and Practice. John Wiley, New York, USA.

17. Langenfeld JJ, Hawthorne SB, Miller DJ (1996) Quantitative analysis of fuelrelated hydrocarbons in surface water and wastewater samples by solidphase microextraction. Anal Chem 68: 144-155.

18. Zang Z, Yang MJ, Pawliszyn J (1994) Solid phase microextraction. A solvent free alternative for sample preparation. Anal Chem 66: 844A-853A.

19. Metafaa M, Economoub A (2013) Chemometrical development and comprehensive validation of a solid phase microextraction/gas chromatography-mass spectrometry methodology for the determination of important free and bound primary aromatics in Greek wines. J of Chromatography A 1305: 244-258.

20. Kataoka H, Lord HL, Pawliszyn J (2000) Applications of solid-phase microextraction in food analysis. J Chromatogr A 880: 35-62.

21. Ouyang G, Pawliszyn J (2006) SPME in environmental analysis. Anal Bioanal Chem 386: 1059-1073.

22. Fatch I (2006) SPME-metal fiber assemblies. The reporter (Europe).

23. Mehdinia A, Mousavi MF (2008) Enhancing extraction rate in solid-phase microextraction by using nano-structured polyaniline coating. J Sep Sci 31: 3565-3572.

24. Mehdinia A, Aziz-Zanjani MO (2013) Recent advances in nanomaterials utilized in fiber coatings for solid-phase microextraction. Trends Anal Chem 42: 205-215.

25. Gbatu TP, Sutton KL, Caruso JA (1999) Development of nerw SPME fibers by sol-gel technology for SPME-HPLC determination of organometals. Anal Chim Acta 402: 67-79.

26. Ferna'ndez-Alba AR (2004) Chromatographic-Mass Spectrometric Food Analysis for Trace Determination of Pesticide Residues. Amsterdam, The Netherlands.

27. Beltran J, López FJ, Hernández F (2000) Solid-phase microextraction in pesticide residue analysis. J Chromatogr A 885: 389-404.

28. Poole CF, Poole SK (1996) Trends in extraction of semivolatile compounds from solids for environmental analysis. Anal Commun 33: $11 \mathrm{H}-14 \mathrm{H}$.

29. Dean JR (1998) Extraction Methods for Environmental Analysis. Wiley, New York.

30. Sousa S, Jiménez-Guerrero P, Ruiz A, Ratola N, Alves A (2011) Organochlorine pesticides removal from wastewater by pine bark adsorption after activated sludge treatment. Environmental Technology 32: 673-683.

31. Lee MR, Lee RJ, Lin YW, Chen CM, Hwang BH (1998) Gas-phase postderivatization following solid-phase microextraction for determining acidic herbicides in water. Anal Chem 70: 1963-1968.

32. Eisert R, Levsen KJ (1995) Determination of organophosphorus, trizazine and 2,6-dinitroanaline pesticides in aqueous samples via solid-phase microextraction (SPME) and gas chromatography with nitrogen-phosphorus detection. Fresenius J Anal Chem 315: 555-562.

33. Boyd-Boland AA, Magdic S, Pawliszyn JB (1996) Simultaneous determination of 60 pesticides in water using solid-phase microextraction and gas chromatography-mass spectrometry. Analyst 121: 929-937.
34. Batlle R, Sanchez C, Nerin C (1999) A systematic approach to optimize solidphase microextraction. Determination pesticides in ethanol/water mixtures used as food stimulant. Anal Chem 71: 2417-2412.

35. Lee XP, Kumazawa T, Sato K, Suzuki O (1996) Detection of organophosphate pesticides in human body fluids by headspace solid-phase microextraction (SPME) and capillary gas chromatography with nitrogen-phosphorus detection. Chromatographia 42: 135-40.

36. Pitarch E, Egea S, Beltran J, Lopez FJ, Hernandez F (1999) Presented at the 11th Meeting of Spanish Society for Analytical Chemistry. Valencia.

37. Rosenfeld J (2002) Recent development in the chemistry and application of analytical derivatization in sampling and sample preparation for field and laboratory. Elsevier, Amsterdam.

38. Menezes A, Filho FN, dos Santos PA, de Paula Pereira (2010) Development validation and application of a methodology based on solid-phase micro extraction followed by gas chromatography coupled to mass spectrometry SPME/GC-MS) for the determination of pesticide residues in mangoes. Talanta 81: 346-354.

39. Volante M, Pontello M, Valoti L, Cattaneo M, Bianchi M, et al. (2000) Application of solid phase micro-extraction (SPME) to the analysis of pesticide residues in vegetables. Pest management science 56: 618-636.

40. Zambonin CG, Quinto M, De Vietro N, Palmisano F (2004) Solid-phase microextraction - gas chromatography mass spectrometry: A fast and simple screening method for the assessment of organophosphorus pesticides residues in wine and fruit juices. Food Chem 86: 269-274.

41. Zambonin CG, Losito I, Cilenti A, Palmisano F (2002) Solidphase microextraction coupled to gas chromatography-mass spectrometry for the study of soil adsorption coefficients of organophosphorus pesticides. J of Environmental Monitoring 4: 477-481.

42. Henriksen T, Svensmark B, Lindhardt B, Juhler RK (2001) Analysis of acidic pesticides using in situ derivatization with alkylchloroformate and solid-phase microextraction (SPME) for GC-MS. Chemosphere 44: 1531-1539.

43. Stalikas CD, Fiamegos YC (2008) Microextraction combined with derivatization. TrAC Trends in Analytical Chemistry 27: 533-542.

44. Pawliszyn J (2000) Theory of solid-phase microextraction. J Chromatogr Sci 38: $270-278$.

45. Boccacci MM, Vanessa G, Elena T, Valentina C (2013) Direct ImmersionSolid Phase Microextraction for the Determination of Chlorinated Pesticide Residues in Tomatoes by Gas Chromatography with an Electron Capture Detector. J of AOAC International 96: 1430-1434.

46. Abdulra'uf LB, Hammed WA, Tan GH (2012) SPME fibers for the analysis of pesticide residues in fruits and vegetables: A review. Critical Rev in Anal Chem 42: 152- 161

47. Lambropoulou DA, Albanis TA (2002) Headspace solid phase microextraction applied to the analysis of organophosphorus insecticides in strawberry and cherry juices. J Agric Food Chem 50: 3359-3365.

48. Pawliszyn J (2009) Handbook of Solid Phase Microextraction. Chemical Industry Press of China, Beijing, China.

49. Gilbert-López B, García-Reyes JF, Molina-Díaz A (2009) Sample treatment and determination of pesticide residues in fatty vegetable matrices: a review. Talanta 79: 109-128.

50. Bruheim I, Liu X, Pawliszyn J (2003) Thin-film microextraction. Anal Chem 75: $1002-1010$

51. Ho H, Lee R, Lee M (2008) Purge-assisted headspace solid-phase microextraction combined with gas chromatography-mass spectrometry for determination of chlorophenols in aqueous samples. J Chromatogr A 1213 245-248.

52. Jimenez JJ, Bernal JL, del Nozal MJ, Martin MT, Mayorga AL (1998) Supercritical fluid extraction offluvalinate residues in honey, determination by high-performance liquidchromatography. J Chromatogr A 829: 269-277.

53. Valor I, Molto JC, Apraiz D, Font G (1997) Matrix effects on solid-phase microextraction of organophosphorus pesticides from water. Journal of Chromatography A 767: 195-203. 
Citation: Tan GH, Low KH, Awoniran A (2015) Use of SPME and Chemometrics in Method Development for Food and Environmental Analysis of Pesticide Residues. Chem Sci J 6: 110. doi:10.4172/2150-3494.1000110

54. Aguilar C, Penalver S, Pocurull E, Borrull F, Marce RM (1998) Solid-phase microextraction and gas chromatography with mass spectrometric detection for the determination of pesticides in aqueous samples. J Chromatogr A 795 105-115.

55. Beltran J, Lopez FJ, Cepria O, Hernandez F (1998) Solid-phase microextraction for quantitative analysis of organophosphorus pesticides in environmental water samples. J Chromatogr A 808: 257-263.

56. Jinno K, Muramatsu T, Saito Y, Kiso Y, Magdic S, et al. (1996) Analysis of pesticides in environmental water samples by solid-phase micro-extractionhigh-performance liquid chromatography. J Chromatogr A 754: 137-144.

57. Bartak P, Cap L (1997) Determination of phenols by solid-phase microextraction. J Chromatogr A 767: 171-175.

58. Eisert R, Pawliszyn J (1997) Design of automated in tube solid phase microextraction coupled to high performance liquid chromatography. J Chromatogr 776: 293-303.

59. Chen Y, Pawliszyn J (2006) Miniaturization and automation of an internally cooled coated fiber device. Anal Chem 78: 5222-5226.

60. Carasek E, Pawliszyn J (2006) Screening of tropical fruit volatile compounds using solid-phase microextraction (SPME) fibers and internally cooled SPME Fiber. J Agric Food Chem 54: 8688-8696.

61. Carasek E, Cudjoe E, Pawliszyn J (2007) Fast and sensitive method to determine chloroanisoles in cork using an internally cooled solid-phase microextraction fiber. J Chromatogr A 1138: 10-17.

62. Wu J, Mullett WM, Pawliszyn J (2002) Electrochemically controlled solidphase microextraction based on conductive polypyrrole films. Anal Chem 74 : 4855-4859.

63. Yates BJ, Temsamani KR, Ceylan Ö, Öztemiz S, Gbatu TP, et al. (2002) Electrochemical control of solid phase micro-extraction: conducting polyme coated film material applicable for preconcentration/ analysis of neutral species. Talanta 58: 739-745.

64. Ding LY, Yuan D (2011) Electrosorption-enhanced solid-phase microextraction of trace anions using a platinum plate coated with single-walled carbon nanotubes. Talanta 85: 1148-1153.

65. Moliner-Martínez Y, Prima-Garcia H, Ribera A, Coronado E, Campíns-Falcó $P$ (2012) Magnetic in-tube solid phase microextraction. Anal Chem 84: 72337240

66. Hung $\mathrm{C}, \mathrm{Ho} \mathrm{H}$, Lin M, Chen $\mathrm{C}$, Shu Y, et al. (2012) Purge-assisted headspace solid phase microextraction combined with gas chromatography/mass spectrometry for the determination of trace nitrated polycyclic aromatic hydrocarbons in aqueous samples. J Chromatogr A 1265: 1-6.

67. Gorecki T, Pawliszyn J (1995) Sample Introduction Approaches for Solid Phase Microextraction/Rapid GC. Anal Chem 67: 3265-3274.

68. Alder L, Greulich K, Kempe G, Vieth B (2006) Residue analysis of 500 high priority pesticides: better by GC-MS or LC-MS/MS? Mass Spectrom Rev 25 838-865.

69. EU Pesticides Database (2012).

70. Fillion J, Sauvé F, Selwyn J (2000) Multiresidue method for the determination of residues of 251 pesticides in fruits and vegetables by gas chromatography/ mass spectrometry and liquid chromatography with fluorescence detection. J AOAC Int 83: 698-713

71. Stan HJ (2000) Pesticide residue analysis in foodstuffs applying capillary gas chromatography with mass spectrometric detection. State-of-the-art use of modified DFG-multi method S19 and automated data evaluation. J Chromatogr A 892: 347-377.

72. Hernando MD, Aguera A, Fernandez-Alba AR, Piedra L, Contreras M (2001) Gas chromatographic determination of pesticides in vegetable samples by sequential positive and negative chemical ionization and tandem mass spectrometric fragmentation using an ion trap analyser. Analyst 126: 46-51.

73. ISO Guide (1997) Calibration of chemical analysis and use of certified reference material. International organization for standardization, Geneva, Switzerland, 32

74. Massart DL, Vandeginste BGM, Buydens LMC, De Jong S, Lewi PJ, et al (1997) Handbook of Chemometrics and Qualimetrics. Part A. Amsterdam, The Netherlands: Elsevier Science.
75. Christensen $\mathrm{JH}$, Hansen $\mathrm{AB}$, Karlson U, Mortensen J, Andersen $\mathrm{O}$ (2005) Multivariate statistical methods for evaluating biodegradation of mineral oil. $J$ Chromatogr A 1090: 133-145.

76. Lavine BK, Vesanen A, Brzozowski DM, Mayfield HT (2001) Authentication of fuel spill standards using gas chromatography/pattern recognition techniques. Anal Lett 34: 281-293.

77. Lewis G, Mathieu D, Phan-Tan-Luu R (1998) Pharmaceutical Experimental Design. Marcel Dekker, New York.

78. Geladi P (2003) Chemometrics in spectroscopy. Part 1. Classical chemometrics. Spectrochimica Acta 58: 767-782.

79. Hanrahan G, Montes R, Gomez FA (2008) Chemometric experimental design based optimization techniques in capillary electrophoresis: a critical review of modern applications. Analytical and Bioanalytical Chemistry 390: 169-179.

80. Leardi R (2009) Experimental design in chemistry: A tutorial. Anal Chim Acta 652: $161-172$

81. Otto M (1999) Chemometrics: statistics and computer applications in analytical chemistry. Wiley-VCH, Chichester.

82. Salafranca J, Domeño C, Fernández C, Nerin C (2003) Experimental design applied to the determination of several contaminants in Duero River by solidphase microextraction. Anal Chim Acta 477: 257-267.

83. Abdul-Rauf LA (2013) Determination of multiclass pesticide residue in fruits and vegetables with head space solid phase microextraction gas chromatography mass spectrometry using experimental factorial design. Malaysia.

84. Costa LM, Ferreira SLC, Nogueira ARA, Nobrega JA (2005) Use of factorial design for optimization of microwave-assisted digestion of lubricating oils. $J$ Braz Chem Soc 16: 1269-1274.

85. Costa LM, Korn MGA, Castro JT, Santos WPC, Carvalho EV, et al. (2006) Factorial design employed for microwave-assisted digestion of beans samples. Quim Nova 29: 149-152.

86. Mousavi M, Noroozian E Jalali-Heravi M, Mollahosseini A (2007) Optimization of solid-phase microextraction of volatile phenols in water by a polyanilinecoated Pt-fiber using experimental design. Analytica Chimica Acta 581: 71-77

87. Doron J, Garcia R, Millán E (2002) Optimization of headspace solid-phase microextraction by means of an experimental design for the determination of methyl tert.-butyl ether in water by gas chromatography-flame ionization detection. Journal of Chromatography A 963: 259-264.

88. Amvrazi EG, Tsiropoulos NG (2009) Chemometric study and optimization of extraction parameters in single-drop microextraction for the determination of multiclass pesticide residues in grapes and apples by gas chromatography mass spectrometry. J Chromatogr A 1216: 7630-7638.

89. Borges CN, Bruns RE, Almeida AA, Scarminio IS (2007) Mixturemixture designs for the fingerprint optimization of chromatographic mobile phases and extraction solutions for canellia sinensis. Anal Chim Acta 595: 28-37.

90. Montgomery DC (2005) Design and analysis of experiments. 6th edn. John Wiley, New York, USA.

91. Kenneth RB, Bruce RK (1987) An introduction to multivariate calibration and analysis. Anal Chem 59: 1007A-1017A.

92. Harald M, Tormod N (1991) Multivariate Calibration. John Wiley, New York USA.

93. Pripp AH, Kieronczyk A, Stepaniak L, Sorhaug T (1999b) Comparison of the biochemical characteristics of three Norwegian cheese varieties using multivariate statistical analysis. Milchwissenschaft 54: 558-562.

94. García-Rodríguez D, Carro AM, Lorenzo RA, Fernández F, Cela R (2008) Determination of trace levels of aquaculture chemotherapeutants in seawater samples by SPME-GC-MS/MS. J Sep Sci 31: 2882-2890.

95. Aguilar C, Peñalver A, Pocurull E, Ferré J, Borrull F, et al. (1999) Optimization of solid-phase microextraction conditions using a response surface methodology to determine organochlorine pesticides in water by gas chromatography and electron-capture detection. Journal of Chromatography A 844: 425-432.

96. Bordagaray A, Garcia-Arrona R, Millán E (2011) Optimization of Solid-Phase Microextraction Procedure Coupled to GC-ECD for Triazole Fungicides Determination in Juice Samples. Food Analytical Methods 4: 293-299. 
Citation: Tan GH, Low KH, Awoniran A (2015) Use of SPME and Chemometrics in Method Development for Food and Environmental Analysis of Pesticide Residues. Chem Sci J 6: 110. doi:10.4172/2150-3494.1000110

Page 8 of 8

97. Zhou Y, Jiang Q, Peng Q, Xuan D, Qu W (2007) Development of a solid phase microextraction-gas chromatography-mass spectrometry method for the determination of pentachlorophenol in human plasma using experimental design. Chemosphere 70: 256-262.

98. Rodrigues FM, Mesquita PRR, Oliveira LS, Oliveira FS, Filho AM, et al. (2011) Development of a headspace solid-phase microextraction/ gas chromatography-mass spectrometry method for determination of organophosphorus pesticide residues in cow milk. Microchemical Journal 98 : 56-61.

99. Rial OR, Yagüe RC, Cancho GB, Simal GJ (2002) Solid-phase microextraction- gas chromatographic-mass spectrometric method for the determination of the fungicides cyprodinil and fludioxonil in white wines. J Chromatogr A 942: 41-52.

100. Navarro S, Barba A, Navarro G, Vela N, Oliva J (2000) Multiresidue method for the rapid determination--in grape, must and wine--of fungicides frequently used on vineyards. J Chromatogr A 882: 221-229.

101. Alvarez MF, Llompart M, Lamas JP, Lores M, Garcia-Jares C, et al. (2008) Development of a solid-phase microextraction gas chromatography with microelectron-capture detection method for a multiresidue analysis of pesticides in bovine milk. Anal Chim Acta 617: 37-50. 